\title{
Cancer patients treated with intravenous chemotherapy for the first time. What are their needs? What do they lack? A qualitative- quantitative mixed approach
}

This article was published in the following Dove Press journal:

Patient Preference and Adherence

\author{
Max-Adrien Garcia' \\ Julie Kalecinski' \\ Mathieu Oriol 1,2 \\ Armand Bonne' \\ Mohamed Lofti ${ }^{1}$ \\ Sophie Espenel ${ }^{3}$ \\ Fabien Tinquaut ${ }^{\prime}$ \\ Pierre Fournel ${ }^{4}$ \\ Olivier Collard ${ }^{4}$ \\ Cécile Vassal ${ }^{4}$ \\ Romain Rivoirard ${ }^{4}$ \\ Véronique Regnier ${ }^{1,5}$ \\ Franck Chauvin $1,2,5$ \\ Aurélie Bourmaud ${ }^{1,5}$ \\ 'Hygee Center, Lucien Neuwirth \\ Cancer Institut, INSERM - CIC-EC, \\ CIC 1408, Saint Priest en Jarez, \\ France; ' Jean Monnet University, \\ Saint Etienne, France; ${ }^{3}$ Radiotherapy \\ Department, Lucien Neuwirth Cancer \\ Institut, Saint Priest en Jarez, France; \\ ${ }^{4}$ Medical Oncology Department, \\ Lucien Neuwirth Cancer Institut, \\ Saint Priest en Jarez, France; ${ }^{5}$ Quality \\ Safety Performance in Health \\ (HESPER) EA7425, Lyon I University, \\ Lyon, France
}

Correspondence: Aurélie Bourmaud Hygee Center, Lucien Neuwirth Cancer Institut, INSERM - CIC-EC, CICl408, 108 bis Avenue Albert Raimond, 42270 Saint Priest en Jarez, France

Tel +3347 79| 7477

Email aurelie.bourmaud@inserm.fr

\begin{abstract}
Introduction: The announcement of cancer coupled with initiation of its treatment impacts patients' psychological and physical states as well as their lifestyles. The objective of this study was to identify and confirm the needs of patients starting off on anticancer chemotherapy treatment
\end{abstract}

Methods: This study was based on a qualitative-quantitative mixed method. In 2009, a qualitative study was conducted at the Lucien Neuwirth Cancer Institut for cancer patients undergoing intravenous chemotherapy for the first time. Exploratory and semi-directed interviews were carried out by a sociologist. In 2014, a questionnaire was hetero-administered to 100 patients starting off on chemotherapy.

Results: Forty patients were interviewed in 2009. Ninety-seven patients answered the questionnaire in 2014. Food was a theme that was identified by a majority of patients in 2009 (13/40) and confirmed in 2014: 63\% needed help in identifying favorable food and $67 \%$ in identifying those that had to be avoided. The other needs identified were those linked to better understanding of the treatment, of how it may affect the couple, its side effects, hygiene and beauty, and knowledge about other treatments. These needs were confirmed in 2014 . New needs were elicited in 2014: activities and leisure (33\%), psychological needs (32.6\%), and family relations (29.9\%).

Conclusion: This study enabled us to identify, confirm, and enrich our knowledge of the needs of cancer patients starting off on intravenous chemotherapy. These results led to the modification of an existing patient education program for these patients, in order to fulfill their needs in an updated and tailored manner.

Keywords: assessment of needs, patients' needs, cancer, patient education, mixed qualitativequantitative method, psychosocial needs

\section{Introduction}

In France, each year 355,000 people face the announcement of cancer. ${ }^{1}$ The announcement of the diagnosis of cancer is perceived as a crystallizing event, threatening the immediate survival of the individual and provoking anxiety. Following the diagnosis of cancer, up to $50 \%$ of individuals develop disorders related to depression and anxiety. ${ }^{2,3}$ The moment the patients discover their disease, they begin the process of acceptance of the disease. ${ }^{4}$ This process is particularly true with regard to cancer; it offsets a multitude of feelings that affect the patient deeply. These feelings are independent from the initial vital risk. ${ }^{5}$ Modifications in the quality of life, psychic wellness, 
and personal representations appear. ${ }^{6-9}$ Family relations are also modified by the diagnosis of cancer. ${ }^{10}$

Moreover, immediately after the announcement of the disease, the patients must cope with other stressful elements, such as the treatments proposed to them. Among these, the most common method of treatment administration is intravenous (IV) chemotherapy. Chemotherapy independently creates a psychological burden for the patients, ${ }^{11}$ not only because of the complexity of its administration but also because of its undesirable effects. ${ }^{12}$ It is currently recommended that patients undergoing chemotherapy have access to psychosocial support in order to compensate for these stressful elements. Thus, the disease and its treatment are cumulative factors of distress for patients. They also modify the order and the nature of their needs (in terms of desire, or related to the feeling that something essential is lacking). ${ }^{13}$

It is often difficult for health professionals to identify these needs during treatment: there is no correlation between symptoms related to the disease and the needs of the patient. ${ }^{14}$ When concordance between the needs felt by the patients and the perception of these needs by the medical community is studied, ${ }^{15,16}$ conclusions are that whatever be the role of the professional (doctor, nurse), he/she is not able to correctly predict the nature of the needs of the patient, nor the hierarchy of these needs as regards the burden that they represent.

To identify these needs in order to fulfill them, the only solution is to get this information from the patients themselves. However, patients do not necessarily have conscious knowledge of their needs nor the facility to express them. The elicitation of these needs thus requires a more in-depth exploration. A simple open question would not be efficient. Qualitative studies, carried out by means of interviews and communication skills, where verbatim are explored and analyzed with a socio-anthropological approach, make it possible to achieve this objective. ${ }^{15}$ By taking all the words and ideas of the patients into account, the complexity of the situations can be summarized and key themes can be identified and classified. This first step allows professionals to obtain a comprehensive overview of the patients' needs.

Patients' needs are an essential element that need to be collected in order to construct an intervention aiming at improving the patients' quality of life. Among actions recommended to enhance patients' quality of life, health care providers are encouraged to develop patient education programs. Patient education is any set of planned, educational activities designed to improve patients' health behavior and/or health status. The purpose of patient education is to maintain or improve health or, in some cases, to slow down deterioration. ${ }^{17}$ Guidelines for best provision of care as regards cancer patient education recommend, in the construction process of a patient education program, first assessing patients' needs and then providing care based on patient needs. This method ensures the construction of a tailored program. ${ }^{18}$ Indeed, patient education enables the transfer of necessary skills to the patient, skills that he/she uses in order to cope with the encountered difficulties. ${ }^{19,20}$ In addition, the conduction of such a program should be a cyclic process, so that the congruence between the program objectives and patients' needs can be continually assessed and corrected.

In the Comprehensive Cancer Center of Saint Étienne, ICLN, a patient education program construction was set up through this recommended process. In 2009, a qualitative study, using interviews, was conducted in order to genuinely elicit the needs of the patients, as regards the initiation of their treatment. A patient education program was then developed, according to these needs, as recommended. In 2014, the question about the congruence of this 2009 program and needs of the 2014 patients was raised. Indeed, patients and their representations evolve over the course of time, alongside cultural, social, and technological modifications.

A second study was then established, using a quantitative collection method, in order to reevaluate patients' needs. This method allowed us to reach a broader and more representative sample of patients, thus enabling update of the patients' needs in 2014.

This study assumes that by following guidelines, and with a comprehensive methodology, the reevaluation of patients' needs through time is 1) feasible and 2) should confirm and even improve the quality of care delivered to them.

The objective of this study was to report the needs of cancer patients starting off on IV chemotherapy, originally identified with a qualitative exploration, and then to quantitatively confirm these needs, later, with a larger number of patients.

\section{Methods}

We carried out two transverse studies at the Lucien Neuwirth Cancer Institut of Saint Etienne. The first study took place in 2009 , the second in 2014.

\section{Qualitative study}

From June to November 2009, a qualitative study was carried out. The studied population was composed of patients who came to the day-hospital of Lucien Neuwirth Cancer Institut for their first chemotherapy treatment (June 2009). The aim 
of the study was to collect the needs of the patients in the course of treatment, these needs arising from their experience with the chemotherapy administered at the center. The secondary objectives were to identify the skills that the patients could put into practice and/or those they wished to acquire, for better management of their chemotherapy. Data collection was carried out by a sociologist. The usual sample size recommended for qualitative research aiming at identifying individuals' needs is around $30 .^{21}$ This sample size reduces the probability under $5 \%$ of missing one major need. We decided to recruit 40 patients for the confirmatory interviews, in order to deal with the lost to follow-up cases (patients who decide not to be recorded or who decide to withdraw after the interview). Twelve open, exploratory interviews (four individual and three focus group interviews) were initially carried out, in order to identify general needs and expectations elicited by the patients. The analysis of these first interviews made it possible to identify a set of themes to which priority should be given, in the context of IV chemotherapy, as well as to build an interview grid. The identified themes were then explored during directive and confirmatory interviews with 40 patients ( 30 women and 10 men - no withdrawals were recorded). The exploratory interviews of 45-60 minutes took place in the day-hospital or in the homes of the patients. The 40 directive interviews of 30-45 minutes took place in the day-hospital.

\section{Quantitative study}

Between February 2014 and January 2015, a survey, conducted by means of a questionnaire, was carried out. All major patients, coming to the day-hospital for their first or second cure of chemotherapy, were consecutively included. Patients who had already taken part in a session of therapeutic education and patients under supervision or trusteeship were excluded. The patients answered a self-managed questionnaire, put up by our team. It gathered the items retained by the patients at the time of our qualitative study in 2009 as well as additional questions coming from the "Supportive Care Needs Survey" questionnaire, in its short and validated French version (SNCS-SF34-FR). ${ }^{20,22}$ It enables evaluation of the needs of patients afflicted with any type of cancer, by using the Likert 5-point scale (1 non-applicable, 2 satisfied, 3 weak, 4 average, and 5 high). Additional questions chosen from the SNCS-SF34-FR were questions 1-15, question 17, 23, 24, 26, 29, and 30. Those questions concerned physical and daily needs, psychological needs, sexual needs, and some of the health system and information needs tackled by the SNCS-SF34-FR. Questions created by the local research team dealt with specific expectations: concerning education programs, activities and actions proposed to patients in the cancer institute, and questions about the integration of and interaction with relatives. All questions in the final questionnaire used the SNCS-SF34-FR answering format: for each question, patients had to answer the following question: "Over the past month, as regards "item," what was your level of need for help?" Patients could choose among a scale ranging from "satisfied" to "high need." In addition, the patients' socio-professional state, as well as the location of the primitive cancer, and the treatment received, were collected. An open-ended question, inviting the patients to express themselves freely, was added. The final questionnaire was created by a multidisciplinary team made up of a sociologist, an oncologist, a methodological doctor, and an experimenter. This questionnaire was tested with five patients as a pretest in order to validate its comprehension.

\section{Analysis}

In order to carry out the qualitative analysis, anonymized interviews were recorded and transcribed into a synthetic transcript by the sociologist who led the interviews. The results were analyzed and compared, according to the groundwork suggested by Miles and Huberman. ${ }^{23} \mathrm{~A}$ thematic analysis of the directed interviews was then made, using the themes from the interview grid. The totality of the data was coded. An analysis of the contents for each theme as well as a comparative analysis of the data were then carried out. Data saturation was searched for and validated through this process.

For the quantitative analysis, we planned to include 100 patients in accordance with the recommendations of European Organisation for Research and Treatment of Cancer (EORTC) ${ }^{24}$ EORTC developed guidelines for quality questionnaire development. In those guidelines, for the psychometric validation of a questionnaire, EORTC recommended that "a few hundred patients" should be recruited. Considering that a part of our questionnaire had already been validated and that our primary objective was not the validation of the questionnaire but the search for representativeness, we calculated a conservative sample size based on expected precision: to obtain a CI of $95 \%$, a precision at $10 \%$ for the most conservative proportion of an expected answer (50\%), 96 patients are needed..$^{25}$ In order to take invalid questionnaires into account, we decided to recruit 100 patients. The statistical analysis was descriptive, the quantitative variables were expressed as a percentage, and missing data were reported. 
The study was approved by the ethics committee of Saint Etienne University Hospital on January 20, 2014 (No IRBN052014/CHUSTE). All participants provided oral informed consent for inclusion, as required by the French law and French ethics rules.

\section{Results}

\section{Socio-anthropological analytical study}

At the time of the qualitative study carried out in 2009, we included 12 patients during the exploratory interviews: eight women and five men. Three of them were accompanied by their spouses. Then, we included 40 patients in the individual interviews: 30 women and 10 men, with an average age of 65.5 years.

The themes identified from the thematic analysis of the exploratory interviews were the following: comprehension of the treatment and its side effects, comprehension of blood tests. How to handle alternative therapies? How to handle food? How to handle marital relationships, as well as family and social relations? How to handle hygiene and beauty? In what physical and leisure activities should they partake? How to handle housework?

The focus groups made it possible to enrich these results by adding further information and explanations. The greatest needs among patients included 1) food, whether viewed as a difficulty or an accompaniment for the healing process; 2) to have a better understanding of their treatment, patients saying that they had received a lot of information but had not initially been able to retain it all; 3) how to handle marital relation: patients fearing that the disease may transform the latter;
4) comprehension of side effects: several side effects were evoked, but those which had caused the greatest discomfort to the patients were those which were the least known and those they had not been prepared for; 5) how to handle hygiene and beauty: patients evoking the need for beauty advice (following the physical deterioration caused by the treatment), and also more general advice on well being; 6) other therapies: patients wishing for more information on therapies like homeopathy, acupuncture, or osteopathy. Having more information on the blood test was finally not reported as being a need. The patients would also have appreciated advice on possible actions for the support of relatives.

The results of the interviews are reported in the form of verbatim in Table 1 .

\section{Quantitative study}

We included 97 patients, of which 65 were women and 32 were men, with an average age of 60.2 years.

We included 22 patients who were undergoing concomitant radiotherapy. The most frequent cancers were those of the digestive system and breast cancer (18.6\% and $44.3 \%$, respectively). Table 2 describes the population included in the study of 2015.

The answers to the questionnaire are presented in Table 3. They are classified in descending order. Thus, the first theme of needs relates to food. Respectively, $66.7 \%$ and $65.5 \%$ of patients reported the need for advice concerning food that are to be favored or avoided. The second theme reported by the patients is physical and leisure activities. In all, $46.9 \%$ of them need to be informed about activities that are favorable,

Table I Results of the qualitative study expressed in verbatim

\begin{tabular}{|c|c|}
\hline $\begin{array}{l}\text { Topics most frequently } \\
\text { approached } \\
\text { N (\%) }\end{array}$ & Associated verbatim \\
\hline Food $13(32.5)$ & $\begin{array}{l}\text { "I encountered many problems because when I was having chemotherapy, I had many mouth ulcers." } \\
\text { "I ate because it was necessary to eat, I had to keep up my strength. But I had no pleasure eating." } \\
\text { "What foods are recommended or which may help us to get better?" because they speak about it between } \\
\text { patients but "everyone gives their two-pence worth. It's hard to know what is true and what is not." }\end{array}$ \\
\hline $\begin{array}{l}\text { Have a better understanding } \\
\text { of the treatment I I (27.5) }\end{array}$ & "Doctors' jargon is not always easy to understand." \\
\hline Marital relation $9(22.5)$ & $\begin{array}{l}\text { "It is a need but patients do not necessarily have the courage to talk about it." } \\
\text { "Our roles had totally switched. I was completely dependent on him." }\end{array}$ \\
\hline Side effects 9 (22.5) & $\begin{array}{l}\text { "We have few explanations. We are warned about visible things only." } \\
\text { "We do not know which problems are linked to chemotherapy or not. I tend to associate everything with } \\
\text { chemotherapy." } \\
\text { "I panicked and I would have preferred to have been warned." }\end{array}$ \\
\hline Hygiene and beauty 9 (22.5) & $\begin{array}{l}\text { "There is already an aesthetician but it is not really enough. She needs to be here more often." } \\
\text { "I was given beauty care here. That went very well. It did me a lot of good." } \\
\text { "I would like to have read more information on the loss of our eyebrows." }\end{array}$ \\
\hline Other therapies 9 (22.5) & "We feel a bit ashamed asking about them. We do not know if it's a good thing." \\
\hline
\end{tabular}


Table 2 Characteristics of the population included in 2014

\begin{tabular}{|c|c|}
\hline $\begin{array}{l}\text { Description of the } \\
\text { studied population }\end{array}$ & Number (\%) \\
\hline Age, years (mean \pm SD) & $60.2 \pm 12.3$ \\
\hline \multicolumn{2}{|l|}{ Gender } \\
\hline Male & $32(33.0)$ \\
\hline Female & $65(67.0)$ \\
\hline \multicolumn{2}{|l|}{ Marital status } \\
\hline Single & $23(23.7)$ \\
\hline Couple & $74(76.3)$ \\
\hline \multicolumn{2}{|l|}{ Dependent children } \\
\hline Yes & $27(27.8)$ \\
\hline No & $70(72.2)$ \\
\hline \multicolumn{2}{|l|}{ Level of school education } \\
\hline Without study diploma & $26(26.8)$ \\
\hline Diploma & $37(38.1)$ \\
\hline A-levels & $17(17.5)$ \\
\hline Bachelor's degree & $14(14.4)$ \\
\hline NA & $3(3.1)$ \\
\hline \multicolumn{2}{|l|}{ Professional status } \\
\hline Retired & $48(49.5)$ \\
\hline Employed & $17(17.5)$ \\
\hline Unemployed & $6(6.2)$ \\
\hline Management position & $6(6.2)$ \\
\hline Housewife & $5(5.2)$ \\
\hline Factory worker & $5(5.2)$ \\
\hline Others & $10(10.3)$ \\
\hline \multicolumn{2}{|l|}{ Type of cancer } \\
\hline Breast & $43(44.3)$ \\
\hline Digestive system & $18(18.6)$ \\
\hline External genital organs & $10(10.3)$ \\
\hline Lung & $7(7.2)$ \\
\hline ENT & $6(6.2)$ \\
\hline Blood & $3(3.1)$ \\
\hline Urological & $3(3.1)$ \\
\hline Cerebral & $\mathrm{I}(\mathrm{I})$ \\
\hline Others & $5(5.2)$ \\
\hline NA & $\mathrm{I}(\mathrm{I})$ \\
\hline \multicolumn{2}{|l|}{ Radiotherapy } \\
\hline Yes & $22(22.7)$ \\
\hline
\end{tabular}

Abbreviations: NA, not applicable; ENT, ear, nose, and throat.

in order to feel better. Finally, the third theme relates to psychological needs. Herein, $44.3 \%$ of the patients have feelings of uncertainty related to the future and $43.3 \%$ are afraid of their capacity of controlling the consequences of their treatment. None of the patients added a comment within the open-ended question.

We compared the results obtained in 2009 and 2014; these are reported in Table 4. The six themes identified in 2009 were all found to be major themes in 2014: from $21.1 \%$ to $64.6 \%$ of the patients reported them. In Table 4 , answers have been reported in means and not frequencies, this is why the numbers in tables 3 and 4 differ. That is why proportions in Tables 3 and 4 differ. Three new topics emerged from the questionnaires in 2014: requirements in occupations and leisure activities ( $33 \%$ of the patients), psychological needs $(32.6 \%)$, and the need related to interaction with family and friends $(29.9 \%)$. Needs relating to pain are not expressed much $(15.5 \%)$.

\section{Discussion}

The aim of this study was to reevaluate, in a population of patients undergoing IV chemotherapy, patients' needs through time. The results of this study underline the persistence of some major needs in this population: the needs concerning food to favor/to avoid are still present, and come first in the list (13.5\% in 2009 and $66.7 \%$ in 2014). They are thus a need which is unsatisfied in patients undergoing cancer treatment. Needs related to the understanding of the treatment and its side effects are still reported and are at the top of the list as well (27.5\% and $22.5 \%$ in 2009 vs $43 \%$ and $42.7 \%$ in 2014): as explained in the qualitative study of 2009 , patients were informed about these two issues but they do not recall them clearly. This raises the issue concerning the agenda of the announcement process. Needs relative to handling their relationship with others are still reported, but with a slight adjustment: the close relation to their partner $(22.5 \%$ in 2009) now extends to the wider circle of relatives (36.8\% in 2014). Hygiene and beauty as well as alternative therapies are reported in 2014 (25.3\% and 26\%), proportionally less than in 2009 (both 22.5\%). Two major new needs arose from the 2014 survey: physical activities and psychosocial needs (35.4\% and 34\%). Firstly, these results underlined that the majority of needs expressed are related to the daily lives of patients, and not to their care or disease management, from a biomedical point of view. Health care providers experience difficulties in addressing "nonhospital" needs, and this is confirmed here. Secondly, the major needs that were elicited in 2009 remain present in 2014. Thirdly, new needs arose in 2014, although it is not easy to comprehend if they are truly emerging needs or simply needs that were provoked and self-produced by the questionnaire itself. Even if they are self-produced needs, it does not mean that they should not be addressed with a newly adapted patient education program, since they have been reported all the same.

The principal need identified at the time of the qualitative study was "food." This topic is present in our 2014 survey and remains the first need expressed by the patients. The need to have a better understanding and control of undesirable side effects of the treatment is quoted in 2009 and in 2014, but it gained importance in 2014. The four other needs are present in exactly the same proportions (a little $>20 \%$ of the 
Table 3 Results of the study carried out in 2014: unsatisfied needs in patients

\begin{tabular}{|c|c|c|}
\hline Unmet needs of patients & $\mathbf{N}(\%)$ & NA \\
\hline Knowing which food to avoid & $64(66.7)$ & I \\
\hline Knowing which food to favor & $60(62.5)$ & I \\
\hline Being informed on what you can do to feel better & $45(46.9)$ & I \\
\hline Uncertainty faced with the future & $43(44.3)$ & 0 \\
\hline Fear of not being able to control the consequences of treatment & $42(43.3)$ & 0 \\
\hline Workshop on the theme "management of the treatment's side effects" & $4 I(43.2)$ & 2 \\
\hline Receiving written information on how to manage the disease and its side effects & $4 \mathrm{I}(42.7)$ & I \\
\hline Fear that cancer spreads & $40(4 I .2)$ & 0 \\
\hline Worries linked to the concern of family and friends & $35(36.8)$ & 2 \\
\hline Knowing how to interpret the blood tests & $35(36.5)$ & 1 \\
\hline Receiving written information on the important aspects of care & $34(35.4)$ & I \\
\hline Being informed about the possibility to participate or not participate in certain activities & $34(35.4)$ & I \\
\hline Anxiety & $33(34.0)$ & 0 \\
\hline Learning how to feel that you are handling the situation & $32(33.0)$ & 0 \\
\hline Offering workshops to those close to you, in which they may participate & $31(32.6)$ & 2 \\
\hline Lack of energy/fatigue & $31(32.0)$ & 0 \\
\hline Receiving information about how to manage your illness and side effects by means of diagrams, drawings, & $30(31.2)$ & 1 \\
\hline \multicolumn{3}{|l|}{ DVDs, Internet, group sessions } \\
\hline Combatting feelings of ill-being & $28(28.9)$ & 0 \\
\hline Not being capable of doing the things you did before & $30(30.9)$ & 0 \\
\hline Receiving information about important aspects related to care: diagrams, drawings, DVDs, Internet, group sessions & $29(30.1)$ & I \\
\hline Feelings of sadness & $28(28.8)$ & 0 \\
\hline Feeling of being prostrate or depressed & $27(27.8)$ & 0 \\
\hline $\begin{array}{l}\text { Allowing your family or friends to have access to support and/or advice from professionals (psychologists, social } \\
\text { assistants, ...) }\end{array}$ & $26(27.1)$ & 1 \\
\hline \multicolumn{3}{|l|}{ (beautician, nutritionist, etc) } \\
\hline Keeping a positive attitude & $25(26.0)$ & I \\
\hline Learning to accept your "own image of yourself" & $24(25.3)$ & 2 \\
\hline Workshop on the theme "hygiene and beauty" & $24(25.3)$ & 2 \\
\hline Your feelings when you think about death or the fact of dying & $22(23.0)$ & I \\
\hline Obtaining beauty care advice in order to mask the effects of the treatment and illness & $21(21.9)$ & I \\
\hline Daily household tasks & $20(20.6)$ & 0 \\
\hline Facing changes in libido & $19(20.4)$ & 4 \\
\hline Adapting to changes in roles in your marital life and/or your home & $19(19.8)$ & I \\
\hline Pain & $15(15.5)$ & 0 \\
\hline Regaining the same relation with your partner that you had before & 14 (14.9) & 3 \\
\hline Workshop on the theme "management of private life" & $14(14.6)$ & I \\
\hline
\end{tabular}

Abbreviation: NA, not applicable.

Table 4 Summary of themes that were retained in the exploratory study of 2009 and those addressed in the quantitative study in 2014

\begin{tabular}{|c|c|c|}
\hline Themes & $\begin{array}{l}\text { Expressed in } \\
2009, \mathrm{n}(\%) \\
\mathrm{N}=40\end{array}$ & $\begin{array}{l}\text { Expressed in } \\
2014, n(\%) \\
N=97\end{array}$ \\
\hline Food & $13(32.5)$ & $62(64.6)$ \\
\hline $\begin{array}{l}\text { Having a better understanding } \\
\text { of the treatment }\end{array}$ & II (27.5) & $26(27.1)$ \\
\hline Relationship within the couple & $9(22.5)$ & $20(2 I . I)$ \\
\hline Side effects & $9(22.5)$ & $37(38.1)$ \\
\hline Hygiene and beauty & $9(22.5)$ & $23(23.7)$ \\
\hline Other therapies & $9(22.5)$ & $25(26)$ \\
\hline Activities and leisure & & $32(33)$ \\
\hline Psychological needs & & $31.3(32.6)$ \\
\hline Relation with family and friends & & $29(29.9)$ \\
\hline Pain & & $15(15.5)$ \\
\hline
\end{tabular}

patients for each topic). With regard to the search for new needs, those that were not identified in 2009 and included in the investigation of 2014, three major sets of themes emerged from the closed questions: psychological needs, those concerning leisure activities, as well as needs related to dealing with friends and family. These had not been mentioned spontaneously in 2009 but are present in 2014, concerning almost one patient out of three. There are several explanations for the appearance of these needs between 2009 and 2014: either they were truly not experienced by the patients in 2009 and have "appeared" since, or it is the society that has evolved (those needs which were difficult to express in 2009 have since lost their taboo and are easier to admit in 2014). The final reason may be the manner in which the data 
were collected: an open interview where needs are expressed spontaneously does not systematically induce answers on behalf of the patients, whereas it may do so in a questionnaire where a list of themes is proposed from the start.

The strengths of this study lie in the methodology used. The qualitative study allowed for the apprehension of the varying complexities of patients' needs. Indeed, the concept of need is a subjective notion, having multifactorial origins and multiple facets, with almost as many combinations as there are patients. Summarizing, connecting, synthesizing, and classifying these expressions and then translating them into needs is a task that human and social sciences execute with specific skills. Thus, the results of 2009 display a level of finesse, precision, and exhaustiveness that would be difficult to obtain using other instruments of measure. With regard to the survey done in 2014, it ensures the validity of the obtained results, thanks to its standardized approach. It also makes it possible to identify new needs. Thanks to the sample size, it ensures greater generalization of the latter. On the one hand, the combination of the two approaches ensures, over the course of time, the robustness of the six principal needs that are elicited, and on the other, it raises questions such as what is the best method in terms of getting patients to elicit their needs? Is it the combination of both that allows a comprehensive overview? Or is it only the replication of measurement over time?

Using this methodological approach, our study is the first, to our knowledge, to explore the complexity of the needs of patients receiving chemotherapy for the first time, following the announcement of cancer. Moreover, it is the first that is concerned with the evolution of these needs in the course of time. It is also the most recent: literature relating to this subject is rather dated and thus does not follow the societal evolution of recent years. The idea that the needs of these particular patients may have evolved since these first studies is confirmed by our own results: in 2014, four new families of needs emerged, needs that were not present in 2009. In particular, needs related to the relatives of patients and those related to physical and leisure activities are in adequacy with the evolution of society. This is a plea to follow patient education guidelines for the quality of care: programs must be developed and reassessed according to patients' needs.

Mulders et al, in $2008,{ }^{26}$ with the Comprehensive Needs Assessment Tool (CNAT) questionnaire, assessed the needs among 80 cancer survivors (no longer in treatment). They identified six of the 10 needs that our study brings to light. Needs relative to food, marital relation, side effects, hygiene and beauty, relation with friends and family, and psychological needs were identified. And yet, patients were cancer survivors with more experience in the disease. Except for Mulders et al, literature has seldom found the same needs nor found as many needs as us: in 2011, Shim et al used the CNAT to identify needs in a population of 2,661 patients. ${ }^{27}$ At least 5 months had passed since their cancer diagnosis, and they were currently under treatment. Among such a large sample, they identified, like us, the needs relative to food in $64.6 \%$ of patients and the needs concerning treatment and its side effects in $58.5 \%$. Other needs identified in this study were care centered: particularly, the need for information about management of side effects of treatment. Perhaps because the Lucien Neuwirth Cancer Institut offers numerous counseling and patient education programs, those needs, related to care, are not so prevalent in our peculiar population. In 2005, Farrell et al (with 33 patients) $)^{15}$ using the Concern Checklist Questionnaire among only female patients, treated for IV chemotherapy, identified psychological needs as well as those related to the couple. In 2003, to explore the needs of patients hospitalized for cancer treatment, Tamburini et al used a mixed methodology where qualitative and quantitative studies were carried out at the same time, in 1 single day (Needs Evaluation Questionnaire for 182 patients and exploratory interview for eight patients). ${ }^{28} \mathrm{He}$ identified the needs related to food, and treatment and its side effects. In contrast to our research, these authors identified needs that our study did not find: two of them elicited needs of financial bearing (Tamburini et al and Farrell et al). ${ }^{15,28}$ This is probably due to the various health care systems explored through those studies and their different reimbursement policies: the Italian and English populations may have limited health coverage protection in comparison to the French population, where all care is covered by a national insurance policy. Correspondingly, Tamburini et al identified needs related to feelings of solitude, linked to the lack in dialog with the oncologist, as well as needs of religious bearing. ${ }^{28}$ These needs were not reported in our study. In addition, Mulders et al revealed a need related to the loss of intellectual concentration and linked to the appearance of a handicap ${ }^{26}$ found nowhere else. On the other hand, none of these authors reported needs related to activity, leisure, or other therapies. This again raises the issue of the questionnaires and suggested answers induced by them.

Our study presents a limitation concerning the methods used for data collection. Indeed, during Phase II, the needs were collected with a questionnaire made up of closed questions. It is thus possible that this tool prompted specific answers because of its structure. Perhaps, non-existing needs 
were brought to the attention of the patients. Yet, for four of the six needs expressed in 2009, the proportions gathered remained the same as those in 2013. Correspondingly, the new needs resulting from the study carried out in 2014 had been mentioned by the patients during exploratory interviews, even if they had not been retained in the results of the qualitative study since they were marginal comments. Thus, they do not appear from nowhere. Moreover, for the quantitative study, we used a questionnaire which had been validated and which has therefore previously demonstrated reliable psychometric capacities. Another limitation of this study is the fact that the data were collected in a monocentric manner. Due to this fact, it is more difficult to validate the generalization of the results to the total population of patients under IV chemotherapy, especially since this cancer center has a long history of patient counseling and education. However, the results of this study are globally in concordance with the literature.

This study enabled us to identify and validate the principal needs of patients starting off on treatment by IV chemotherapy. New needs were elicited: needs related to the psychological state, relations with relatives, and physical activity. The pragmatic consequence of this study was the reevaluation of the contents of the patient education program. It now contains two additional sessions: one dedicated to physical activity and one to stress management and relaxation techniques. Moreover, this study confirms the necessity of reevaluating the objectives of a health education intervention. The tailoring of a program is one of the key elements in the provision of quality care for patient education programs. This tailoring implies an ongoing cyclic process of the assessment of needs coupled with intervention adaptation. Patient education programs should not be static in their phase of construction. They should evolve with their population.

\section{Availability of data and material}

Individual interviews' transcriptions cannot be made available because it could compromise participants' individual privacy. Data from the 2014 survey are available from the authors upon request.

\section{Acknowledgment}

The authors would like to thank Susan Guillaumond (Activenglish) for translation and editing services funded by Hygee Center, France.

\section{Author contributions}

All authors contributed toward data analysis, drafting and critically revising the paper, gave final approval of the version to be published, and agree to be accountable for all aspects of the work.

\section{Disclosure}

The authors report no conflicts of interest in this work.

\section{References}

1. Binder-Foucard F, Bossard N, Delafosse P, et al. Cancer incidence and mortality in France over the 1980-2012 period: solid tumors. Rev Epidemiol Sante Publique. 2014;62(2):95-108.

2. Parle M, Jones B, Maguire P. Maladaptive coping and affective disorders among cancer patients. Psychol Med. 1996;26(4):735-744.

3. Ford S, Lewis S, Fallowfield L. Psychological morbidity in newly referred patients with cancer. J Psychosom Res. 1995;39(2):193-202.

4. Burnet K, Robinson L. Psychosocial impact of recurrent cancer. Eur J Oncol Nurs. 2000;4(1):29-38.

5. Griffin IS, Fentiman M. Psychosocial problems following a diagnosis of breast cancer. Int J Clin Pract. 2002;56(9):672-675.

6. Wilson TR, Alexander DJ, Kind P. Measurement of health-related quality of life in the early follow-up of colon and rectal cancer. Dis Colon Rectum. 2006;49(11):1692-1702.

7. Patel D, Sharpe L, Thewes B, Bell ML, Clarke S. Using the distress thermometer and Hospital Anxiety and Depression Scale to screen for psychosocial morbidity in patients diagnosed with colorectal cancer. $J$ Affect Disord. 2011;131(1-3):412-416.

8. Sharpe L, Patel D, Clarke S. The relationship between body image disturbance and distress in colorectal cancer patients with and without stomas. J Psychosom Res. 2011;70(5):395-402.

9. Simard S, Thewes B, Humphris G, et al. Fear of cancer recurrence in adult cancer survivors: a systematic review of quantitative studies. J Cancer Surviv. 2013;7(3):300-322.

10. Cassileth BR, Steinfeld AD. Psychological preparation of the patient and family. Cancer. 1987;60(3 Suppl):547-552.

11. Michael M, Tannock IF. Measuring health-related quality of life in clinical trials that evaluate the role of chemotherapy in cancer treatment. CMAJ. 1998;158(13):1727-1734.

12. Sharma R, Tobin P, Clarke SJ. Management of chemotherapy-induced nausea, vomiting, oral mucositis, and diarrhoea. Lancet Oncol. 2005; 6(2):93-102.

13. Tamburini M, Gangeri L, Brunelli C, et al. Assessment of hospitalised cancer patients' needs by the Needs Evaluation Questionnaire. Ann Oncol. 2000;11(1):31-37.

14. Osse BH, Vernooij-Dassen MJ, Schadé E, Grol RP. The problems experienced by patients with cancer and their needs for palliative care. Support Care Cancer. 2005;13(9):722-732.

15. Farrell C, Heaven C, Beaver K, Maguire P. Identifying the concerns of women undergoing chemotherapy. Patient Educ Couns. 2005;56(1): $72-77$.

16. Heaven CM, Maguire P. Disclosure of concerns by hospice patients and their identification by nurses. Palliat Med. 1997;11(4):283-290.

17. CPEN. Establishing comprehensive cancer patient education programs: standards of practice. 2013. Available from: http://www. cancerpatienteducation.org/docs/CPEN/Educator\%20Resources/ CPENStandardsofPractice.Nov14.pdf. Accessed June 18, 2018.

18. Régnier-Denois V, Rousset-Guarato V, Nourissat A, Bourmaud A, Chauvin F. Contribution of a preliminary socio-anthropological survey to the development of a therapeutic patient education programme for patients receiving oral chemotherapy. Educ Thér Patient/Ther Patient Educ. 2010;2(2):S101-S107.

19. Piredda M, Rocci L, Gualandi R, Petitti T, Vincenzi B, De Marinis MG. Survey on learning needs and preferred sources of information to meet these needs in Italian oncology patients receiving chemotherapy. Eur J Oncol Nurs. 2008;12(2):120-126. 
20. Boyes A, Girgis A, Lecathelinais C. Brief assessment of adult cancer patients' perceived needs: development and validation of the 34-item Supportive Care Needs Survey (SCNS-SF34). J Eval Clin Pract. 2009; 15(4):602-606.

21. Griffin A, Hauser JR. The voice of the customer. Mark Sci. 1993; 12(1):1-27.

22. Brédart A, Kop JL, Griesser AC, et al. Validation of the 34-item Supportive Care Needs Survey and 8-item breast module French versions (SCNS-SF34-Fr and SCNS-BR8-Fr) in breast cancer patients. Eur J Cancer Care (Engl). 2012;21(4):450-459.

23. Qualitative Data Analysis: A Methods Sourcebook. Third Edition. Miles MB, Michael Huberman AM, Saldana J, editors. Thousand Oaks: SAGE Publications, Inc; 2014.

24. Johnson C, Aaronson N, Blazeby JM, et al. EORTC Quality of Life Group; Guidelines for Developing Questionnaire Modules; 2011; Fourth edition. Available from: http://groups.eortc.be/qol/sites/default/ files/archives/guidelines_for_developing_questionnaire-_final.pdf. Accessed August 30, 2018.
25. Naing L, Winn T, Rusli BN. Practical issues in calculating the sample size for prevalence studies. Arch Orofac Sci. 2006;1:9-14.

26. Mulders M, Vingerhoets A, Breed W. The impact of cancer and chemotherapy: perceptual similarities and differences between cancer patients, nurses and physicians. Eur J Oncol Nurs. 2008;12(2):97-102.

27. Shim EJ, Lee KS, Park JH, Park JH. Comprehensive needs assessment tool in cancer (CNAT): the development and validation. Support Care Cancer. 2011;19(12):1957-1968.

28. Tamburini M, Gangeri L, Brunelli C, et al. Cancer patients' needs during hospitalisation: a quantitative and qualitative study. BMC Cancer. 2003;3:12.

\section{Publish your work in this journal}

Patient Preference and Adherence is an international, peer-reviewed, open access journal that focuses on the growing importance of patient preference and adherence throughout the therapeutic continuum. Patient satisfaction, acceptability, quality of life, compliance, persistence and their role in developing new therapeutic modalities and compounds to optimize clinical outcomes for existing disease states are major areas of interest for the journal. This journal has been accepted for indexing on PubMed Central. The manuscript management system is completely online and includes a very quick and fair peer-review system, which is all easy to use. Visit http://www. dovepress.com/testimonials.php to read real quotes from published authors.

Submit your manuscript here: http://www.dovepress.com/patient-preference-and-adherence-journal 